\title{
CARACTERIZAÇÃO DA PRODUÇÃO DE PEQUI EM JAPONVAR, MG
}

\author{
Sandra Regina Afonso ${ }^{1}$, Humberto Angelo ${ }^{2}$, Alexandre Nascimento de Almeida ${ }^{3}$ \\ ${ }^{1}$ Serviço Florestal Brasileiro, Brasília, Distrito Federal, Brasil - afonsandra @ gmail.com \\ ${ }^{2}$ Universidade de Brasília, Departamento de Engenharia Florestal, Brasília, Distrito Federal, Brasil - humb@unb.br \\ ${ }^{3}$ Universidade de Brasília, Faculdade de Planaltina, Brasília, DF, Brasil - alexalmeida @unb.br \\ Recebido para publicação: 21/10/2013 - Aceito para publicação: 28/05/2014
}

\begin{abstract}
Resumo
A utilização de produtos florestais não madeireiros vem sendo amplamente discutida como uma importante estratégia para o desenvolvimento sustentável local e a conservação ambiental, na medida em que a sua produção contribui para a organização comunitária, gera renda às comunidades envolvidas e estimula a manutenção da biodiversidade. A partir da experiência da Cooperativa de Produtores Rurais e Catadores de Pequi de Japonvar (COOPERJAP), Minas Gerais, Brasil, desenvolve-se estudo sobre a importância da atividade na geração de trabalho, renda, capacitação e organização comunitária. A utilização do pequi acarreta ainda a inclusão da questão ambiental na discussão pública. Os resultados indicaram uma grande importância socioeconômica da atividade para a região, fortalecendo a cooperativa em estudo, gerando renda e oportunidade de emprego para a população jovem.

Palavras-chave: Caryocar brasiliense; economia florestal; desenvolvimento regional.
\end{abstract}

\begin{abstract}
Characterization of Pequi production from Japonvar, $M G$. The use of non timber forest products has been widely discussed as an important strategy for local sustainable development and environmental conservation, to the extent that their production contributes to community organization, generates income for the communities involved and encourages the maintenance of biodiversity. The Cooperative of Agricultural Producers and Collectors of Pequi of Japonvar (COOPERJAP), Minas Gerais, Brazil, develops researches on the importance of the activity in generating jobs, income, training and community organization. The use of pequis still results in the inclusion of environmental issues in the public discussion. The results indicated a great socio-economic importance of the activity for the region, strengthening the cooperative, generating income and employment opportunities for young people.

Keywords: Caryocar brasiliense; forest economy; regional development.
\end{abstract}

\section{INTRODUÇÃO}

Sendo o segundo maior bioma brasileiro, ocupando $24 \%$ do território nacional, o Cerrado se destaca pela grande diversidade de produtos florestais não madeireiros (PFNMs), capazes de gerar significativa renda econômica às populações locais e às indústrias processadoras de seus princípios ativos (PINHEIRO, 2002). Das quase 12 mil espécies de plantas registradas no bioma, pelo menos 200 possuem algum potencial econômico. Sob o ponto de vista do agroextrativismo, destacam-se espécies popularmente conhecidas, como pequi, baru, mangaba, cagaita, buriti, jatobá, cajuí, arnica, mama-cadela, faveira, gueroba e murici, entre outras. Os frutos in natura e produtos industrializados, como geleias, licores, sucos, compotas, doces, palmito e pequi em conserva, medicamentos, óleos e ornamentos, são comercializados na região Centro-Oeste (EMPRESA BRASILEIRA DE PESQUISA EM AGROPECUÁRIA (EMBRAPA), 2007; OLIVEIRA; SCARIOT, 2011).

A busca de alternativas de utilização e processamento de espécies nativas representa uma importante estratégia para o desenvolvimento econômico sustentável. Nas últimas décadas, vários trabalhos analisaram a utilização de PFNMs à luz de aspectos econômicos, ambientais e sociais (WICKENS, 1991; SANTOS et al., 2003; BOXELL et al., 2003; ENDERS et al., 2006; SCHMIDT et al., 2007). Milhões de pessoas de áreas rurais obtêm uma considerável parte das necessidades básicas e renda com a colheita de PFNMs (ENDERS et al., 2006). Esses produtos cumprem um papel crucial na vida

FLORESTA, Curitiba, PR, v. 45, n. 1, p. 49 - 56, jan. / mar. 2015.

Afonso, S. R.; Angelo, H.; Almeida, A. N. de

ISSN eletrônico 1982-4688 / ISSN impresso 0015-3826 
diária de populações tradicionais, como fonte de importantes insumos, alimentos, remédios, forragem, fertilizantes, energia, fibra, resina, goma e materiais de construção, entre outros (CASTELLANI, 2002; SANTOS et al., 2003).

O uso sustentável da biodiversidade do Cerrado contribui para a conservação dos recursos naturais, como a água, o solo e a própria biodiversidade, uma vez que a valorização dessa biodiversidade constitui forte motivo para preservá-la (CARVALHO, 2006). Diante disso, a utilização dos não madeireiros do Cerrado se torna uma importante estratégia para segurança alimentar, geração de renda, conservação da biodiversidade e desenvolvimento local.

No período de 1980-2010, a ocupação acelerada e desordenada do Cerrado brasileiro acarretou a diminuição territorial desse bioma para quase a metade, gerando discussões relacionadas às alternativas de sobrevivência de suas comunidades, para conciliar desenvolvimento local e conservação dos recursos naturais (EMBRAPA, 2007; OLIVEIRA; SCARIOT, 2011).

De todas as espécies referidas, o pequizeiro, cujo nome científico é Caryocar brasiliense, é uma árvore de médio porte, cujos frutos são chamados de pequi ou piqui, sendo sem dúvida uma das mais importantes árvores do Cerrado, tradicionalmente utilizada pelas populações da região com diversas finalidades, que envolvem várias de suas partes (RIBEIRO, 2000; OLIVEIRA, 2009). Apelidado de "carne dos pobres" e chamado de "esteio do sertão", o pequi tem seu uso principal na forma de alimento altamente nutritivo, devido à riqueza de sua polpa em vitaminas, gorduras e proteínas (POZO, 1997). No Cerrado, comumente ocorrem, em média, 25 pequizeiros por hectare, podendo chegar a 100 em algumas vegetações mais fechadas. O pequizeiro atinge de 7 a $12 \mathrm{~m}$ de altura, com troncos retorcidos e que podem crescer para os lados, às vezes, próximos ao chão (OLIVEIRA; SCARIOT, 2011).

A quantidade de frutos depende muito do tamanho da árvore, principalmente da copa e do tronco. Na região norte de Minas Gerais, os pequizeiros com troncos de DAP superior a $25 \mathrm{~cm}$ produzem o dobro de frutos que as árvores com troncos mais finos. Assim, um pequizeiro produz em média 110 frutos, podendo chegar a 420. Um fruto de pequi pesa entre 30 e $400 \mathrm{~g}$, com comprimento variando de 6 a $14 \mathrm{~cm}$ e diâmetro de 6 a $10 \mathrm{~cm}$. Geralmente, os frutos possuem um ou dois caroços, mas em alguns são encontrados até seis (OLIVEIRA, 2009). Os caroços são cobertos por polpa amarelada, que é a parte mais utilizada na alimentação humana. A coleta do pequi se concentra entre os meses de dezembro e janeiro, período em que as lavouras de grãos já estão plantadas e permitem que, no intervalo entre os tratos culturais, vários membros da família se dediquem a essa atividade (RIBEIRO, 2000). Durante os meses da safra, representa reforço alimentar indispensável na mesa das comunidades do Cerrado, além de apresentar a maior quantidade de vitamina A entre todos os frutos usualmente consumidos no Brasil (POZO, 1997).

O pequi também constitui uma importante fonte de renda monetária para uma parcela da população. Em um dia de trabalho, uma família, formada pelo casal e um filho, pode coletar até $60 \mathrm{~kg}$ de caroços, os quais, quando processados para extração do óleo da polpa, podem render cerca de 6 litros de óleo da polpa, sendo equivalentes a 17 horas de trabalho, ao longo de dois dias. Os agroextrativistas que comercializam sua própria produção conseguem vender o litro de óleo em feiras livres por cerca de $\mathrm{R} \$ 7,00$. Na região norte de Minas, a renda média (valor bruto) de uma família que trabalha com o pequi, principalmente com a comercialização do óleo, é cerca de $\mathrm{R} \$ 450,00$ por safra, o que pode corresponder a $5,5 \%$ da renda anual familiar (OLIVEIRA; SCARIOT, 2011).

Após a colheita dos frutos, é produzido o óleo da polpa, aliado à extração da castanha para paçoca e óleo branco, com fabricação de sabão (RIBEIRO, 2000). Alguns derivados do pequi, como sabão, castanha e remédios, ainda não são comercializados em grande escala, embora apresentem um mercado potencial. $\mathrm{O}$ óleo comestível e o licor destacam-se pela importância econômica alcançada, constituindo-se num mercado em expansão em nível nacional e internacional, gerando emprego permanente e importante contribuição em termos de impostos (POZO, 1997). Recentemente, estudos realizados por Antunes et al. (2006) apontam ainda o óleo do pequi como adequado para a produção de biodiesel.

O estado de Minas Gerais é, atualmente, o segundo maior produtor de pequi no Brasil, tendo uma produção de 1.690 toneladas no ano de 2006 (INSTITUTO BRASILEIRO DE GEOGRAFIA E ESTATÍSTICA (IBGE), 2013), destacando sua política de incentivo da produção iniciada na década de 80. As condições favoráveis da região, a simplicidade da colheita e a facilidade de escoamento da produção, em virtude da proximidade de rodovias, são fatores que contribuem para a atividade. Contudo, devido à colheita do pequi durar apenas três meses, sofre com a falta de condições técnicas produtivas e 
comerciais da comunidade, as quais, por não serem organizadas, permitem a exploração por atravessadores de outras cidades e estados, como Goiás e São Paulo (PEREIRA, 2004).

Nesse contexto, o município mineiro de Japonvar conta com uma população de 8.119 habitantes, sendo 5.542 pessoas da área rural e 2.577 pessoas da área urbana. Em paralelo, conforme relatório do Serviço Brasileiro de Apoio às Micro e Pequenas Empresas (SEBRAE) (2000), pessoas entrevistadas afirmavam que o município apresentava cerca de 600 produtores agropecuários, para os quais o pequi é o produto mais significativo do ponto de vista econômico.

Embora contando com diversas associações rurais no município, em 1998 foi constituída a Cooperativa de Catadores de Pequi de Japonvar (COOPERJAP), com cerca de 120 cooperados, a qual evoluiu para um quadro social com 250 famílias associadas, atualmente. Ressalte-se o fato que inicialmente a comunidade não vislumbrava a forma como uma cooperativa poderia modificar a sua situação econômica e social (PEREIRA, 2004).

A Coooperjap, por meio de uma das associações, a Associação dos Pequenos Produtores Rurais de Cabeceira do Mangaí (APROCAM) é beneficiária desde 2002, pelo Small Grants Programme (SGP), conhecido como Programa de Pequenos Projetos (PPP), de uma linha de apoio a projetos de conservação da biodiversidade. Esse programa viabilizou a construção da Fábrica de Beneficiamento de Frutos do Cerrado na APROCAM. Posteriormente, em 2005, passou a apoiar o Projeto de Desenvolvimento e Exploração Sustentável dos Frutos do Cerrado proposto pela COOPERJAP, de forma a ampliar sua atuação municipal.

O objetivo do presente artigo é analisar as caracteristicas da produção de Pequi pela COOPERJAP em Minas Gerais, visando caracterizar a atividade e identificar a sua importância socioeconômica para a região.

\section{MATERIAL E MÉTODOS}

\section{Área de estudo}

O estudo foi desenvolvido em 2008, na COOPERJAP, situada no município de Japonvar, no norte do estado de Minas Gerais (Figura 1), com área territorial de $377,2 \mathrm{~km}^{2}$, segundo dados do IBGE (2013).

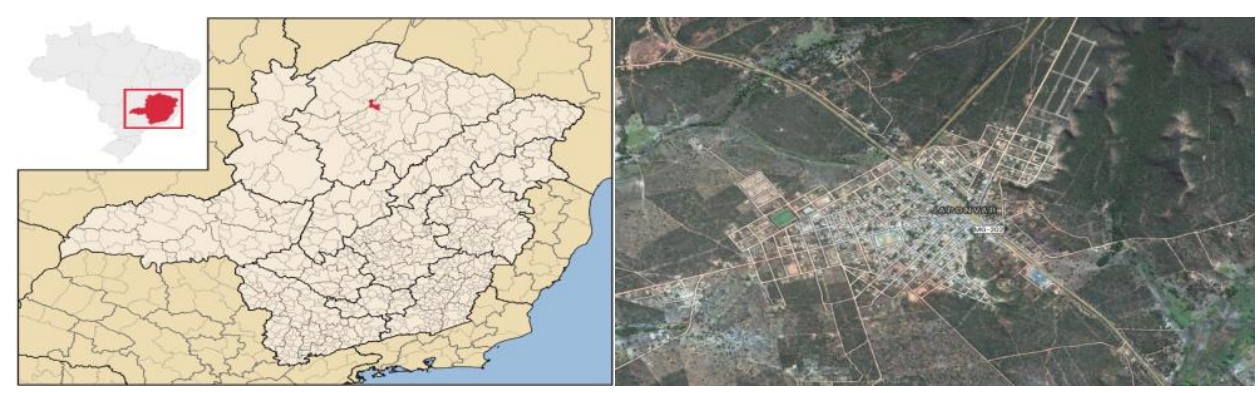

Figura 1. Localização do município de Japonvar em Minas Gerais.

Figure 1. Location of the municipality of Japonvar in Minas Gerais.

Fonte: IBGE (2013)

Atualmente, a atuação da COOPERJAP envolve nove comunidades do município, das quais sete apresentam unidades de processamento de pequi. Nas safras de 2005/06 e 2006/07, a cooperativa teve a participação direta de, respectivamente, 120 e 200 famílias.

\section{Coleta e análise dos dados}

Por meio de observações diretas, aplicação de questionário semiestruturado junto aos cooperados e entrevistas abertas com 12 membros diretores da COOPERJAP, foram obtidos dados da safra de pequi do ano de 2006/07, sobre comportamento qualitativo do setor referentes a cinco aspectos:

- Extração, processamento e comercialização do pequi e outros PFNMs na região do Cerrado.

- Características socioeconômicas dos cooperados.

- Percepção da importância para os cooperados e expectativa da COOPERJAP. 
- Formas de participação dos cooperados na COOPERJAP.

- Percepção dos diretores da COOPERJAP quanto a sua evolução e atuação.

Os questionários aplicados foram testados previamente, envolvendo 5 a $10 \%$ da amostra, a fim de efetuar as adequações nos mesmos, tendo como instrumental analítico a estatística descritiva. Para compreensão da importância e expectativa em relação à COOPERJAP, bem como da participação de seus cooperados, foram feitas questões de múltipla escolha, que os entrevistados deveriam assinalar, para, a partir da quantidade de itens marcados, serem analisadas suas opiniões.

\section{RESULTADOS E DISCUSSÃO}

\section{Estrutura organizacional da COOPERJAP}

No ano de 2006, a COOPERJAP assumiu uma nova forma de administração da cooperativa, de maneira a aumentar a participação das comunidades. Atualmente, apresenta em sua diretoria 13 membros, sendo que cada uma das nove comunidades envolvidas tem no mínimo um representante, com exceção de Cabeceira de Mangaí, onde se localiza a fábrica.

Essa proposta de distribuição de cargos se mostrou bastante eficiente no envolvimento das comunidades mais distantes e principalmente na transmissão das informações. Outro fator de grande importância para ampliar a participação dos cooperados foi a inclusão da COOPERJAP no Programa de Compra e Doação Simultânea para Merenda, da Companhia Nacional de Abastecimento (CONAB), envolvendo 136 cooperados.

\section{Produção da COOPERJAP}

No período de março de 2006 a abril de 2007, haviam sido entregues $9.509 \mathrm{~kg}$ de polpas de frutos do Cerrado, $3.769 \mathrm{~kg}$ de pequi, $2.870 \mathrm{~kg}$ de umbu e $2.870 \mathrm{~kg}$ de coquinho-azedo, correspondendo a quase $25 \%$ do valor total contratual com a Merenda Escolar. Esse projeto foi fundamental para aumentar a participação e envolvimento dos cooperados. Devido a isso, a cooperativa passou por um processo de reorganização, um novo cadastramento foi realizado e os cooperados ultrapassaram o número de 200.

Na mesma safra de 2006/07, a COOPERJAP ampliou sua atuação com os frutos nativos, em comparação ao ano anterior, pois, aos originais araticum, umbu e cagaita, foram adicionados buriti, coquinho-azedo, mangaba, murici e macaúba. Esses produtos foram comercializados na forma de polpas e doces, destinando-se parte aos mercados local, regional e nacional, além da parte inserida no projeto de Compra Antecipada da Agricultura Familiar da CONAB.

Outro importante produto não madeireiro, a fava-d'anta (Dimorphandra mollis, Benth.), frequentemente encontrada na região, passou a ser comercializado a partir de 2006, quando a COOPERJAP entregou 30 toneladas para a indústria farmacêutica Merck. Foram entregues 24 toneladas na safra de 2007.

Em relação ao pequi, na safra de 2006/07, a cooperativa apresentou aumento na produção de polpa, óleo e castanha, quando comparada à safra anterior. Ainda na mesma safra, a COOPERJAP comercializou 1.500 vidros do pequi em caroço, contendo cerca de 10 caroços por vidro (Tabela 1).

Tabela 1. Produtos do pequi produzidos pela COOPERJAP nas safras de 2006 e 2007.

Table 1. Pequi products produced by COOPERJAP in 2006 and 2007.

\begin{tabular}{lccc}
\hline \multirow{2}{*}{ Produto } & \multirow{2}{*}{ Unidade } & \multicolumn{2}{c}{ Safra de pequi } \\
\cline { 3 - 4 } & & $\mathbf{2 0 0 5 / 2 0 0 6}$ & $\mathbf{2 0 0 6 / 2 0 0 7}$ \\
\hline Polpa & $\mathrm{kg}$ & 5.000 & 15.000 \\
Óleo & litro & 1.000 & 2.000 \\
Licor & litro & 600 & 60 \\
Castanha & $\mathrm{kg}$ & 20 & 500 \\
Caroços & vidros & - & 1.500 \\
\hline
\end{tabular}

Fonte: Dados da pesquisa de campo (2008).

\section{O processamento de Pequi pela COOPERJAP}

Das nove comunidades abrangidas pela COOPERJAP, existem unidades de processamento de pequi em sete delas, sendo chamadas de miniunidades de despolpa. Assim, são desenvolvidas atividades de despolpa do fruto e cozimento da polpa, com exceção da comunidade de Cabeceira de Mangaí, onde se localiza a fábrica. 
Nas miniunidades, os cooperados desenvolvem diferentes funções: gerente de produção (coordena o trabalho nas miniunidades); entregadores (fazem a coleta do pequi em carrroças ou carrinhos de mão e levam à unidade); roletadores (trabalham fora dos barracos, retiram a casca do fruto e carregam para despolpa); despolpadores (trabalham dentro dos barracos e retiram a polpa do fruto); cozinheira (trabalham dentro dos barracos, na lavagem, cozimento das polpas com sal e armazenamento).

A produção nas miniunidades ocorre segundo um fluxograma (Figura 2), sendo a remuneração feita conforme a função exercida. Após desenvolvido o processamento preliminar das polpas de pequi, elas são levadas até a fábrica para tratamento físico (choque térmico) e químico (adição de ácido cítrico e benzoato de sódio).

Desde a coleta do pequi até o envase do produto, o processo de produção envolve um grande contingente de mão de obra e agrega valor ao produto. Na fábrica, ocorre o preparo do pequi em caroço, é feita a conserva da polpa e são produzidas as polpas e doces de frutas e o licor.

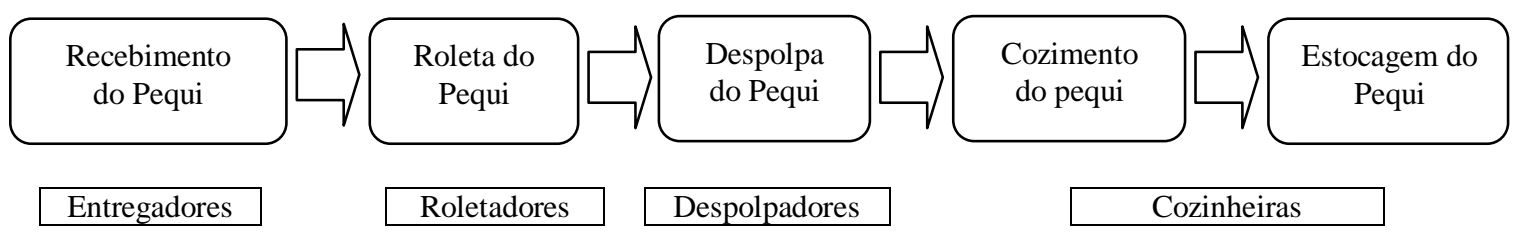

Figura 2. Fluxograma de produção das processadoras de pequi nas miniunidades de despolpa.

Figure 2. Production flowchart of pequi processing in small units pulping.

Os parâmetros de comercialização empregados pela COOPERJAP estabelecem a colocação de 12 a 15 dúzias de pequi por caixa, cujo rendimento industrial é equivalente a dois quilos de polpa, posteriormente transformadas em 11 vidros com 170 gramas de polpa em conserva.

Em paralelo, em valores do ano de 2008, é pago um preço de $\mathrm{R} \$ 2,00$ ao entregador da caixa de pequi e $\mathrm{R} \$ 8,00$ ao gerente por dois quilos de polpa a granel. O valor de $\mathrm{R} \$ 5,00$ é pago pelo consumidor por vidro com polpa em conserva, embora a caixa disponha de 11 unidades a $\mathrm{R} \$ 55,00$. Ou seja, o preço de venda do produto em conserva é cerca de 28 vezes maior do que o valor do pequi em casca. No caso da produção do creme, a polpa é liquefeita após os tratamentos físicos e químicos, para posterior envase e rotulagem.

A fábrica também produz o pequi em caroço, feito a partir da roleta do pequi, cozimento do caroço e posterior tratamento físico e químico. A produção do pequi em caroço é realizada sob encomenda, sendo o produto comercializado em recipientes de vidro com $550 \mathrm{ml}$ de capacidade, contendo 10 caroços, em média.

A comercialização do pequi em caroço emprega pouca mão de obra, gerando menos trabalho e renda aos cooperados. Esse tipo de produto comercializa a castanha, que não é retirada do endocarpo espinhoso do fruto, apresentando coloração branca e um sabor exótico. Pode ser consumida torrada ou in natura, sendo o produto utilizado como ingrediente na elaboração de pratos salgados, doces, sorvetes e pães, ocorrendo destaque pela aceitação no mercado nacional.

A produção da castanha é fator importante para o aproveitamento do recurso, anteriormente desperdiçado, gerando emprego e renda à comunidade. Por isso, um processo simplificado para obtenção da castanha foi desenvolvido pela cooperativa, com a criação de um equipamento manual que divide a amêndoa ao meio, sendo retiradas as duas metades da castanha. Contudo, esse trabalho exige habilidade e atenção, tanto no manejo do equipamento de corte quanto na retirada da castanha do endocarpo espinhoso. Além disso, observa-se um baixo rendimento, pois são necessárias 450 amêndoas para obtenção de $1 \mathrm{~kg}$ de castanha.

$\mathrm{O}$ óleo de pequi é produzido de forma artesanal nas propriedades rurais, embora a COOPERJAP tenha conhecimento técnico e equipamento para a produção na fábrica. A produção caseira é, normalmente, executada pelas mulheres, mesmo sendo uma atividade que exija força. O pequi é cozido por quatro horas no fogão de lenha e então transferido para uma grande gamela, chamada de masseira, onde é "batido e socado" com uma colher de pau. À massa amarelada que se forma é acrescentada, aos poucos, água fria e retirada a nata de óleo que se forma. Essa nata é novamente cozida e envasada em garrafas de vidro. 
A garrafa de 2 litros é comprada pela COOPERJAP junto aos produtores. A cooperativa coa o óleo diversas vezes e, nesse processo, cerca de $15 \%$ é perdido. O produto é envasado em vidros de $50 \mathrm{ml}$, para a comercialização, ou mesmo vendido por litro.

\section{Caracterização dos cooperados das unidades de despolpa}

Entre os cooperados da COOPERJAP, cerca de $69,20 \%$ são proprietários de suas terras e o restante, posseiros. Em sua maioria são jovens de até 20 anos $(42,30 \%)$, sendo que mais da metade $(57,70 \%)$ tem até 30 anos de idade. No que diz respeito às atividades dos cooperados, metade se considera produtor rural, $30,80 \%$ estudante, $11,5 \%$ dona de casa e 7,7\% trabalhador agrícola. Além disso, verificou-se que 26 eram trabalhadores nas miniunidades de despolpa, todos oriundos de apenas duas comunidades.

O nível de escolaridade apresenta uma distribuição em dois grupos distintos: $46 \%$ dos entrevistados com primeiro ciclo do ensino fundamental (até 4 anos de curso) e 54\% com ensino médio (8 a onze anos de curso).

Entre os entrevistados, apenas um produtor tem função de diretoria na COOPERJAP, como gerente de produção, enquanto todos os outros são cooperados. O tempo de participação na cooperativa foi de até quatro anos para $65,40 \%$ dos entrevistados, o que está de acordo com a grande presença de jovens na atividade de processamento do pequi.

Os entrevistados representaram as cinco atividades exercidas dentro da cooperativa: entregadores (16\% do total), roletadores (16\%), cozinheiras (10\%) e o grupo majoritário dos despolpadores $(57,70 \%)$.

Em relação à importância da cooperativa para geração de oportunidades específicas, $88,46 \%$ consideram a geração de emprego e renda como um aspecto importante, seguidos por 34,62\% que citaram a redução na perda de frutas e $15,38 \%$ que indicaram o fornecimento para a merenda.

No tocante às expectativas, $23,08 \%$ dos respondentes esperam a geração de mais emprego e renda e a diversificação na linha de produção, enquanto a continuidade, a melhoria da condição de trabalho e obtenção de equipamentos foram apontados por 11,54\% dos entrevistados.

Especificamente em relação à cooperativa, $92,31 \%$ dos entrevistados consideram o trabalho no processamento uma forma de participação. Metade dos respondentes participa dos cursos de capacitação e $46,15 \%$ frequentam as reuniões e incentivam a entrada de outros cooperados na COOPERJAP.

\section{Percepções da diretoria da COOPERJAP}

Além dos motivos citados pelos cooperados, os diretores mencionam que a atividade traz felicidade, crescimento/desenvolvimento para o município, expectativas de novos projetos coletivos e amplia o diálogo entre o poder público e a sociedade, apresentando uma importância política local.

Em relação às expectativas, citam a ampliação do número de cooperados, aumento da participação dos envolvidos, conquistas de novos projetos e construção de um armazém de estocagem e venda de insumos agrícolas.

Uma das mais importantes conquistas do trabalho cooperativo realizado na coleta do pequi foi a criação de Lei Municipal que proíbe a derrubada do pequi, usando qualquer espécie de equipamento que provoque sua queda prematura, sob pena de apreensão e multa. Em nível estadual, havia sido criada, em 27 de junho de 2001, a Lei nº 13.965, Pró-Pequi, que trata da exploração dos frutos do Cerrado.

Outro importante acontecimento promovido pela COOPERJAP é o Seminário Anual, o qual acontece durante todos os anos no mês dezembro, em Japonvar. O evento reúne diversos municípios da região, colocando em pauta a coleta e utilização do pequi, bem como trabalha na capacitação dos participantes para novos produtos.

\section{CONCLUSÕES}

- O estudo sobre a COOPERJAP evidencia a importância da utilização de não madeireiros para geração de trabalho, renda, capacitação e estímulo à conservação ambiental e à organização comunitária.

- O processamento do pequi envolve a utillização de mão de obra de diversas faixas etárias e níveis de escolaridade, sem que ela tenha de se deslocar de sua comunidade, permitindo o aumento do valor de mercado do produto e ampliação do tempo de comercialização. 
- O trabalho gera oportunidades para os jovens das comunidades rurais, apesar do pouco interesse em participar de outras atividades na cooperativa e poucas expectativas em relação ao futuro da COOPERJAP, requerendo a elaboração de estratégias para aumento do envolvimento deles nas questões decisivas da cooperativa.

- Políticas públicas de incentivo, como o Programa de Compra e Venda Simultânea de Merenda e as leis de proteção ambiental, se mostraram fundamentais para a estruturação da cooperativa.

- O projeto desenvolvido junto à CONAB contribuiu na comercialização dos produtos, embora necessite de incremento e divulgação em veículos de amplo acesso, como internet e feiras.

\section{REFERÊNCIAS}

ANTUNES, E. C.; ZUPPA, NETO T. O.; ANTONIOSI, FILHO N. R.; CASTRO, S. S. Utilização do pequi (Caryocar brasiliense Camb.) como espécie recuperadora de ambientes degradados no cerrado e fornecedora de matéria-prima para a produção de biodiesel. In: I CONGRESSO DA REDE BRASILEIRA DE TECNOLOGIA DE BIODIESEL, 2006, Brasília. Anais..., 2006.

BOXELL, P. C.; MURRAY, G.; UNTERSCHULTZ, J. R. Non-timber forest products from the Canadian boreal forest: an exploration of aboriginal opportunities. Journal of Forest Economics, Umea, v. 9, p. 75 - 96, 2003.

CARVALHO, I. S. H. Desenvolvimento e gestão ambiental para assentamentos rurais no Cerrado. In: III ENCONTRO DA ANPPAS, 2006, Brasília. Anais..., 2006.

CASTELLANI, D. C. Plantas medicinais e aromáticas: produtos florestais não madeireiros (PFNM). In: SEMINÁRIO MATOGROSSENSE DE ETNOBIOLOGIA E ETNOECOLOGIA E II SEMINÁRIO CENTRO-OESTE DE PLANTAS MEDICINAIS, 2002, Cuiabá. Anais..., 2002.

EMPRESA BRASILEIRA DE PESQUISA AGROPECUÁRIA (EMBRAPA). A EMBRAPA nos biomas brasileiros, 2007. Disponível em: <http://ainfo.cnptia.embrapa.br/digital/bitstream/item /82598/1/a-embrapa-nos-biomas-brasileiros.pdf>. Acesso em: 06/11/2013.

ENDERS, B. A.; GORCHOV, D. L.; BERRY, E. J. Sustainability of a non-timber forest product; Effects of alternative leaf harvest practices over 6 years on yield and demografy of the palm Chamaedorea radicalis. Forest Ecology and Management, Fort Collins, v. 234, p. 181 - 191, 2006.

INSTITUTO BRASILEIRO DE GEOGRAFIA E ESTATÍSTICA (IBGE). Disponível em: $<$ http://www.ibge.gov.br/home/>. Acesso em 06/11/2013.

OLIVEIRA, W. L. Ecologia populacional e extrativismo de frutos de Caryocar brasiliense Camb. no Cerrado no norte de Minas Gerais. Brasília, DF. 82 f. Dissertação (Mestrado em Ecologia) Universidade de Brasília, 2009.

OLIVEIRA, W. L. de; SCARIOT, A. Boas práticas de manejo para o extrativismo sustentável do pequi. Brasília: Embrapa Recursos Genéticos e Biotecnologia, 2011. 84 p.

PEREIRA, A. C. S. Pequi: O ouro do Cerrado mineiro. Histórias de sucesso, experiências empreendedoras. Brasília: SEBRAE, 2004. 17 p.

PINHEIRO, C. U. B. Extrativismo, cultivo e privatização do jaborandi (Pilocarpus Microphyllus Stapf ex Holm.; Rutaceae) no Maranhão, Brasil. Revista Acta Botanica Brasilica, Feira de Santana, v. 16, n. 2, p. $141-150,2002$.

POZO, O. V. C. O pequi (Caryocar brasiliense): uma alternativa para o desenvolvimento sustentável do Cerrado no norte de Minas Gerais. 97 f. Dissertação (Mestrado em Administração Rural) - Universidade Federal de Lavras, Lavras, 1997.

RIBEIRO, R. F. Pequi, o rei do Cerrado: roendo o fruto sertanejo por todos os lados. Belo Horizonte: Rede Cerrado/Rede/Caa-nm/Capo-vale, 2000. 62 p. 
SANTOS, A. J.; HILDEBRAND, E.; PACHECO, C. H.; PIRES, P. T. de L.; ROCHADELLI, R. Produtos não madeireiros: conceituação, classificação, valoração e mercados. Revista Floresta, Curitiba, v. 33, n. 2, p. 215 - 224, 2003.

SERVIÇO BRASILEIRO DE APOIO ÀS MICRO E PEQUENAS EMPRESAS (SEBRAE). Diagnóstico Municipal de Japonvar. Montes Claros: Sebrae, 2000.

SCHMIDT, I. B.; FIGUEIREDO, I. B.; SCARIOT, A. Ethnobotany and effects of haversting on the population ecology of Syngonanthus nitens (Bong.) Ruhland (Eriocaulaceae), a NTFP from Jalapão region, Central Brazil. Economic Botany, Nova York, v. 61, n. 1, p. 73 - 85, 2007.

WICKENS, G. E. Management issues for development of non-timber forest products. Unasylva, Roma, v. 42 , n. 165 , p. $3-8,1991$. 